\title{
Intense Therapy in Patients with Locally Advanced Esophageal Cancer beyond Hope for Surgical Cure: A Prospective, Multicenter Phase II Trial of the Swiss Group for Clinical Cancer Research (SAKK 76/02)
}

\author{
Thomas Ruhstaller $^{\mathrm{a}} \quad$ Arnoud Templeton $^{\mathrm{a}}$ Karin Ribi $^{\mathrm{b}} \quad$ Jan C. Schuller ${ }^{\mathrm{b}} \quad$ Markus Borner $^{\mathrm{c}}$ \\ Sandra Thierstein $^{\mathrm{b}}$ Roger von Moos ${ }^{\mathrm{d}}$ Stefanie Pederiva $^{\mathrm{e}} \quad$ Andreas Lohrif $^{\mathrm{f}}$ \\ Norbert Lombriser $^{g} \quad$ Christian von Briel $^{\mathrm{c}} \quad$ Dieter Koeberle $^{\mathrm{a}}$ Razvan Popescu ${ }^{\mathrm{h}}$
}

${ }^{a}$ Kantonsspital St. Gallen,

${ }^{\mathrm{b}}$ Coordination Center of the Swiss Group for Clinical Cancer Research (SAKK), Bern,

${ }^{c}$ Kantonsspital Bern,

${ }^{\mathrm{d}}$ Kantonsspital Chur,

e Kantonsspital Baden,

${ }^{\mathrm{f}}$ Kantonsspital Liestal,

${ }^{9}$ Stadtspital Triemli Zürich,

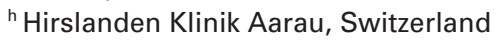

\section{Key Words \\ Esophageal cancer - Inoperable - Locally very advanced . Chemoradiation}

\section{Summary}

Background: There is no standard treatment for patients with locally advanced esophageal carcinoma without systemic metastasis in whom surgery is no longer considered a reasonable option. Patients and Methods: Patients with cervical esophageal tumors, locally very advanced stage (T4 and/or M1a) or locally advanced ( $\mathrm{T} 3$ and/or $\mathrm{N}+$ ) with comorbidities were included. Therapy: 2 cycles of induction chemotherapy (cisplatin and docetaxel, both $75 \mathrm{mg} / \mathrm{m}^{2}$ 3-weekly) followed by chemoradiation therapy (CRT) comprising a total radiation dose of $59.4 \mathrm{~Gy}$ together with docetaxel $15 \mathrm{mg} / \mathrm{m}^{2}$ and cisplatin $25 \mathrm{mg} / \mathrm{m}^{2}$ ( 5 weekly doses). Primary endpoint: Histologically proven freedom from local failure 6 months after CRT completion. Results: 21 patients were included: 12 had locally very advanced tumors, 3 had cervical esophagus tumors, and 6 were medically unfit for surgery. 18 patients completed therapy per protocol. Grade $3 / 4$ toxicities during CRT were thrombopenia (10\%) and dysphagia (15\%). 1 patient died due to herpes simplex infection. The primary endpoint was achieved by 4 patients, 6 were alive after median follow-up of 34 months, and median survival was 16 months. Most patients experienced lasting improvement of dysphagia following induction chemotherapy. Conclusions: This regimen is feasible, showed clinically meaningful, long-lasting improvements in quality of life and resulted in long-term survival in $29 \%$ of the patients.
Schlüsselwörter

Ösophaguskarzinom · Inoperabel ·

Lokal sehr weit fortgeschritten · Radiochemotherapie

\section{Zusammenfassung}

Hintergrund: Es existiert keine Standardbehandlung für Patienten mit Ösophaguskarzinom ohne systemische Metastasierung, bei denen Chirurgie nicht in Betracht kommt. Patienten und Methode: Eingeschlossen wurden Patienten mit zervikalem Ösophaguskarzinom, lokal weit fortgeschrittener Erkrankung (T4 und/oder M1a) oder aus medizinischen Gründen inoperable Patienten mit fortgeschrittener Erkrankung (T3 und/oder $\mathrm{N}+$ ). Nach 2 Zyklen Induktionschemotherapie mit Cisplatin und Docetaxel (jeweils $75 \mathrm{mg} / \mathrm{m}^{2}$ im Abstand von 3 Wochen) wurde eine Chemoradiotherapie (CRT) mit 59,4 Gy und $15 \mathrm{mg} / \mathrm{m}^{2}$ Docetaxel bzw. $25 \mathrm{mg} / \mathrm{m}^{2}$ Cisplatin (jeweils 5 Gaben) durchgeführt. Primärer Endpunkt war histologisch bestätigte lokale Tumorfreiheit 6 Monate nach Abschluss der Radiochemotherapie. Resultate: Von 21 eingeschlossen Patienten hatten 12 ein lokal weit fortgeschrittenes Ösophaguskarzinom, 3 hatten ein zervikales Karzinom und 6 waren aus medizinischen Gründen inoperabel. 18 Patienten erhielten die gesamte Therapie gemäß Protokoll. Die häufigsten Grad-3/4-Toxizitäten während der CRT waren Thrombopenie (10\%) und Dysphagie (15\%). Ein Patient verstarb an einer Herpes-simplex-Hepatitis. 4 Patienten erreichten den primären Endpunkt, nach 34 Monaten Nachbeobachtungszeit waren 6 noch am Leben, das mediane Überleben betrug 16 Monate. Die durch die Patienten erfasste Dysphagie zeigte eine anhaltende Verbesserung nach der Induktionschemotherapie. Schlussfolgerungen: Die geprüfte Therapie war gut durchführbar und zeigte eine klinisch relevante Verbesserung der Lebensqualität sowie ein Langzeitüberleben bei $29 \%$ der Patienten.

\begin{tabular}{ll}
\hline KARGER & @ 2010 S. Karger GmbH, Freiburg \\
Fax +497614520714 & Accessible online at: \\
Information@Karger.de & www.karger.com/onk \\
www.karger.com &
\end{tabular}




\section{Introduction}

Esophageal cancer ranks sixth among the causes of death from cancer worldwide [1]. Most patients with newly diagnosed carcinoma of the esophagus present with potentially resectable, locally advanced disease. The accepted standard treatment for these patients is potentially curative therapy comprising neoadjuvant chemoradiation (CRT) or chemotherapy followed by surgery and definitive CRT [2-5]. A minority of patients present with systemic metastasis at diagnosis and are usually treated with chemotherapy or only palliative care [6]. However, there is a specific group of patients with locally advanced disease, without systemic metastases, in whom the disease is still regional, but surgery is no longer considered a reasonable option because of tumor location (cervical esophagus), very advanced stage (M1a or T4) or poor performance status and comorbidities. Multidisciplinary team meetings to determine the best treatment strategy for such patients usually focus on the difficult question of how much therapy could or should be given when there is no hope for surgical cure. The range of options includes radiotherapy (external beam or brachytherapy), more intensive CRT, systemic chemotherapy, stenting interventions, or only palliative care. Substantial palliation of dysphagia can be achieved despite the often relatively poor condition of such patients; however, most will experience tumor progression at the primary site. There are few prospective trials focusing on this specific population $[7,8]$. Some of these patients deemed to be inoperable have been included in trials of CRT for locally advanced disease [2, 9-11]. These studies provided evidence to suggest improved overall survival for the whole group of patients treated with CRT compared with radiotherapy alone.

Based on these considerations, we initiated a prospective nationwide, multicenter trial to investigate whether an intensive treatment strategy using induction chemotherapy followed by CRT is feasible and beneficial for this specific group of patients with inoperable loco-regional esophageal cancer.

\section{Patients and Methods}

This was a prospective, open-label, multicenter phase II study conducted by the Swiss Group for Clinical Cancer Research (SAKK). The protocol was approved by the local ethics committee of each participating institution, and all patients gave their written informed consent before registration.

\section{Major Eligibility Criteria}

Previously untreated patients with histologically confirmed squamous cell carcinoma or adenocarcinoma of the esophagus were eligible if the tumor was: (1) locally very advanced (T4 and/or M1a), (2) located in the cervical esophageal region, or (3) locally advanced ( $\mathrm{T} 3$ and/or $\mathrm{N}+$ ) but the patient was medically unfit for surgery. All tumor lesions had to be encompassable in a single radiation port. Patients with distant metastases were excluded. Further selection criteria included age between 18 and 70 years, a World Health Organization (WHO) performance status $<2$, and normal organ function.

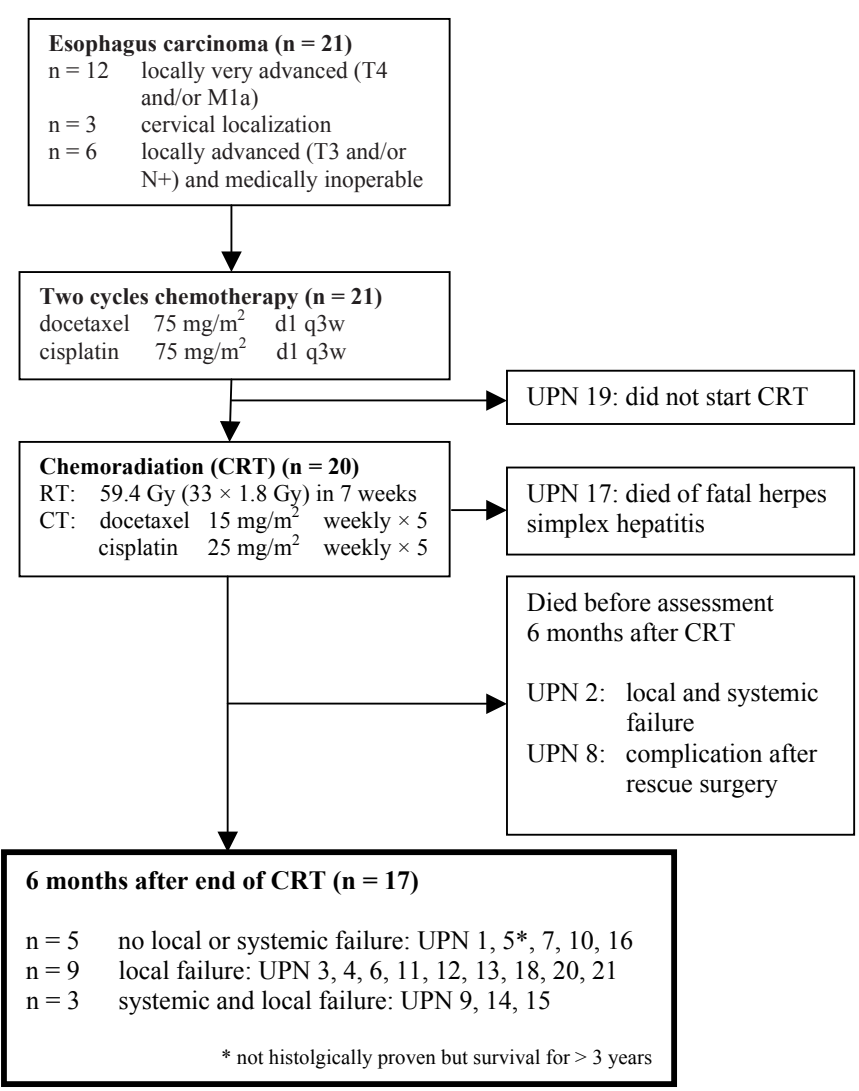

Fig. 1. Treatment plan and outcome.

\section{Treatment Schedule and Evaluation Plan}

Pretreatment staging consisted of complete medical history, physical examination, upper endoscopy with biopsy, helical computed tomography (CT) scans of the chest and abdomen (and neck for cervical or upper third thoracal localization), endoscopic ultrasound (EUS), and bronchoscopy for tumors above or at the tracheal bifurcation. A laparoscopy for tumors of the lower third of the esophagus was optional. Positron emission tomography (PET) or PET-CT staging was recommended, but not mandatory.

Treatment consisted of induction chemotherapy followed by CRT (fig. 1). Induction chemotherapy consisted of 2 cycles of intravenous docetaxel and cisplatin, both $75 \mathrm{mg} / \mathrm{m}^{2}$ on day 1 of a 3 -weekly cycle. CRT was started after completion of the second induction chemotherapy cycle. Three-dimensional (3D) conformal radiotherapy delivering a total dose of $59.4 \mathrm{~Gy}$ ( 33 fractions of $1.8 \mathrm{~Gy}$ ) was given over 7 weeks with a minimal energy of 6-MV photons. The planned target volume included all known areas of disease with a $5-\mathrm{cm}$ cranial and caudal margin and a 2-cm lateral margin. Concomitant chemotherapy consisted of intravenous docetaxel $15 \mathrm{mg} / \mathrm{m}^{2}$ and cisplatin $25 \mathrm{mg} / \mathrm{m}^{2}$ administered weekly for 5 weeks on an outpatient basis.

\section{Dose Modifications and Follow-up}

Toxicity was graded according to the National Cancer Institute - Common Toxicity Criteria (NCI-CTC) version 2.0. In the second induction chemotherapy cycle, cisplatin and docetaxel were both postponed if the absolute neutrophil count (ANC) was $<1500 / \mu$ l or the platelet count was $<100,000 / \mu \mathrm{l}$. Patients were required to have an ANC of $\geq 1000 / \mu \mathrm{l}$ and a platelet count of $\geq 75,000 / \mu \mathrm{l}$ prior to starting CRT. During CRT, docetaxel was omitted for 1 week if the ANC was $<1000 / \mu$ l or the platelet count was $<50,000 / \mu \mathrm{l}$. Radiotherapy and both drugs were omitted for 1 
week if the ANC was $<500 / \mu l$ and/or the platelet count was $<25,000 / \mu 1$ after weekly reassessment. Docetaxel was omitted if febrile neutropenia occurred during CRT, whereas radiotherapy and cisplatin were continued at the discretion of the local investigator. Early insertion of a feeding tube was recommended for patients developing tumor- or treatmentinduced dysphagia. Radiotherapy was continued in patients with grade 3 therapy-induced esophagitis, but the final decision to continue chemotherapy was left to the local investigator. Both chemotherapy and radiation were omitted in patients with grade 4 esophagitis until toxicity resolved to grade 3 .

Cisplatin was replaced by carboplatin in patients developing grade 3 peripheral neuropathy, grade 2 hearing impairment, or creatinine clearance $<50 \mathrm{ml} / \mathrm{min}$. Carboplatin was given at a dose of area under the concentration-time curve (AUC) $6 \mathrm{mg} \cdot \mathrm{min} / \mathrm{ml}$ for the second cycle of induction chemotherapy and AUC $2 \mathrm{mg} \cdot \mathrm{min} / \mathrm{ml}$ throughout CRT. Dose reduction rules were applied for grade 3 nausea, vomiting or diarrhea.

Follow-up including CT scans, physical examination, evaluation of adverse events, and quality-of-life (QoL) assessment was carried out 3-monthly during the first year following completion of CRT, 6-monthly during the next 3 years, and subsequently on an annual basis unless otherwise clinically indicated. Endoluminal ultrasound and endoscopy with at least 4 biopsies of the previous tumor area were scheduled 6 months after completion of CRT. Further endoscopic examinations were performed only in patients presenting with symptoms raising suspicion of local failure.

\section{Endpoints and Criteria for Response and Survival}

The main objective of this trial was to evaluate whether intensive CRT after induction chemotherapy can achieve a high rate of local control with acceptable toxicity and stable QoL in patients with locally advanced esophageal cancer. To test this hypothesis, we selected the primary endpoint 'percentage of patients with histologically proven freedom from local failure 6 months after the last dose of radiotherapy', defined as the absence of primary tumor and any new lesion or recurrence by radiological means within the radiotherapy field. In all patients without signs of tumor, at least 4 biopsies had to be taken from the area of the primary tumor. We defined a feasibility endpoint to evaluate the compliance and toxicity of this treatment. The feasibility endpoint, based on an intentionto-treat analysis, was defined as follows: the proportion of patients alive 30 days after the end of therapy and completing the whole therapeutic regimen comprising 2 cycles of induction therapy and at least 50 Gy of radiotherapy together with at least 4 cycles of weekly concomitant chemotherapy (even if there were dose reductions or only one drug was administered). Overall survival was a secondary endpoint. The pattern of failure was determined by the localization of the tumor at the time of relapse.

\section{Ouality of Life}

Symptom-specific key aspects of QoL in this situation (i.e. dysphagia and problems with eating) were assessed by the European Organisation for Research and Treatment of Cancer (EORTC) QoL module specific to esophageal cancer (QLQ-OES24) $[12,13]$. In addition, two global QoL indicators for physical well-being and coping effort were measured with linear analog self-assessment (LASA) scales [14, 15]. All scales range from 0 to 100 , with higher scores representing more symptoms with respect to dysphagia and eating problems, but better physical well-being and less coping effort.

\section{Statistics}

To evaluate the primary endpoint 'percentage of patients with histologically proven freedom from local failure 6 months after the last dose of radiotherapy', the sample size was calculated to have a power of $80 \%$ and a significance level of $5 \%$ to accept an ineffective treatment. This study used a two-stage design based on Herndon's approach, a modification of Simon's 2-stage design that allows continued accrual while waiting for stage-1 results [16]. A $\geq 50 \%$ rate of freedom from local failure was con- sidered promising for further study and a rate of $<30 \%$ was considered ineffective. The stage- 1 analysis was done after the primary endpoint was evaluable in 15 patients. If $\geq 4 / 15$ patients were failure free, then accrual would continue until a total of 46 patients; otherwise accrual would be suspended and an additional analysis would be carried out on all patients having been enrolled at that time. The results of the additional analysis would determine if the trial should be terminated or continued. Survival analysis was done on an intention-to-treat basis using the Kaplan-Meier method. All QoL scores were reported descriptively. A change of $\geq 8$ points on each scale was considered as clinically meaningful [17].

Serious adverse events and response rates were continuously monitored by the SAKK Coordinating Centre. The interim results were presented to the SAKK Executive Committee before a definitive decision about continuation or early stopping was made.

\section{Results}

\section{Patient and Tumor Characteristics}

The study was stopped prematurely after an interim analysis when 21 patients from 7 Swiss cancer centers were enrolled (table 1). Most patients were men (86\%), the median age was 64.3 years (range 45.8-73.1 years), and 11 had the performance status 0 . PET-CT was used for staging in 14 (67\%) patients. The reasons for inclusion in this trial were as follows: $12(57 \%)$ patients had locally very advanced disease (T4 and/ or M1a), 3 (14\%) had a tumor in the cervical esophagus (T4 in 1$)$, and 6 (29\%) had locally advanced tumors (T3 and/or $\mathrm{N}+$ ) but were medically unfit for surgery. Histology was squamous cell carcinoma in $10(48 \%)$, adenocarcinoma in $8(38 \%)$ and mixed/undifferentiated carcinoma in the remaining cases.

\section{Feasibility and Toxicity}

All 21 patients received 2 full cycles of induction chemotherapy and $18(86 \%)$ received the full course of CRT according to the predefined feasibility endpoint. Peracute fatal herpes simplex hepatitis developed in 1 patient (unique patient number (UPN) 17) 4 weeks after the start of CRT [18]. Another patient (UPN 19) did not start CRT because the tumor volume was too large according to the radiooncologist and, therefore, retrospectively this patient would not have met the trial inclusion criteria. Radiotherapy was stopped early (after $39.6 \mathrm{~Gy}$ ) in a third patient (UPN 15) because the radiooncologist was concerned about intolerable late sequalae resulting from a very large irradiation volume.

The toxicity profile of induction chemotherapy and CRT is listed in table 2. Toxicities during induction chemotherapy were as expected and manageable. Hematologic toxicity was the most common adverse event occurring to some degree in all patients receiving 2 cycles of docetaxel and cisplatin. Second-cycle chemotherapy dose reductions of $25 \%$ were required for docetaxel (1 patient) and both docetaxel and cisplatin ( 2 patients) as a result of infection, weight loss or stomatitis. CRT was well tolerated by most patients. Grade 3/4 thrombopenia occurred in 2 patients and dysphagia in 3 patients. 
Table 1. Baseline characteristics and outcome

\begin{tabular}{|c|c|c|c|c|c|c|c|c|c|}
\hline UPN & $\begin{array}{l}\text { Age, } \\
\text { years }\end{array}$ & Histo & $\mathrm{T}$ & $\mathrm{N}$ & M & Reason & 6 months after CRT & $\begin{array}{l}\text { Cause of } \\
\text { death }\end{array}$ & OS \\
\hline 1 & 55.4 & $\mathrm{SC}$ & uT3 & $\mathrm{uNx}$ & M1a & LVA & no failure & alive & 45.9 \\
\hline 2 & 62.1 & $\mathrm{SC}$ & $\mathrm{uT} 4^{\mathrm{d}}$ & uN0 & M0 & LVA & not alive & tumor & 6.6 \\
\hline 3 & 64.6 & $\mathrm{SC}$ & uT4 & uN1 & M0 & CERV & local failure & tumor & 11.6 \\
\hline 4 & 45.9 & $\mathrm{AC}$ & uT3 & uN1 & M1a & LVA & local failure & tumor & 25.6 \\
\hline 5 & 61.6 & $\mathrm{SC}$ & uT3 & uN1 & M1a & LVA & no failure & alive & 38.2 \\
\hline 6 & 71.3 & ASC & uT3 & uN1 & M0 & MU & local failure & tumor & 20.4 \\
\hline 7 & 69.3 & $\mathrm{AC}$ & $\mathrm{uTx}$ & $\mathrm{uN} 1$ & M1a & LVA & no failure & tumor & 24.9 \\
\hline 8 & 49.1 & $\mathrm{SC}$ & uT3 & $\mathrm{uN} 1$ & M1a & LVA & not alive & other & 8.2 \\
\hline 9 & 64.4 & $\mathrm{AC}$ & uT1 & $\mathrm{uN} 1$ & M0 & $\mathrm{MU}$ & systemic failure & tumor & 9.3 \\
\hline 10 & $73.1^{\mathrm{a}}$ & $\mathrm{AC}$ & uT3 & uN0 & M0 & MU & no failure & alive & 35.6 \\
\hline 11 & 69.5 & undiff & uT4 & $\mathrm{uN} 1$ & M1a & LVA & local failure & other & 13.2 \\
\hline 12 & 55.7 & $\mathrm{AC}$ & uT4 & $\mathrm{uN} 1$ & M0 & LVA & local failure & alive & 31.7 \\
\hline 13 & 68.5 & $\mathrm{SC}$ & uT2 & $\mathrm{uN} 1$ & M0 & MU & local failure & tumor & 14.8 \\
\hline 14 & 62.6 & undiff & uT2 & uN1 & M0 & CERV & systemic failure $^{\mathrm{f}}$ & tumor & 9.9 \\
\hline 15 & 68.1 & $\mathrm{SC}$ & uT3 & $\mathrm{uN} 1$ & M1a & LVA & systemic failure $^{\mathrm{f}}$ & tumor & 19.7 \\
\hline 16 & 50.4 & $\mathrm{AC}$ & $\mathrm{uT2}$ & $\mathrm{uN} 1$ & $M 1 b^{c}$ & LVA & no failure & alive & 28.7 \\
\hline 17 & 68.7 & $\mathrm{AC}$ & uT3 & $\mathrm{uN} 1$ & M0 & $\mathrm{LVA}^{\mathrm{e}}$ & not alive & other & 2.3 \\
\hline 18 & 70.5 & $\mathrm{AC}$ & uT3 & $\mathrm{uN} 1$ & M0 & MU & local failure & alive & 29.4 \\
\hline 19 & 67.5 & $\mathrm{SC}$ & $\mathrm{Tx}^{\mathrm{b}}$ & $\mathrm{N} 1$ & M1a & LVA & no CRT & tumor & 15.2 \\
\hline 20 & 59.4 & $\mathrm{SC}$ & uT3 & $\mathrm{uN} 1$ & M0 & MU & local failure & tumor & 15.8 \\
\hline 21 & 58.5 & $\mathrm{SC}$ & $T x^{b}$ & $\mathrm{~N} 1$ & M0 & CERV & local failure & tumor & 12.3 \\
\hline
\end{tabular}

$\mathrm{AC}=$ adenocarcinoma, $\mathrm{ASC}=$ adenosquamous, $\mathrm{CERV}=$ cervical localization, Histo $=$ histology, LVA $=$ locally very advanced tumor, $\mathrm{M}=$ metastasis, $\mathrm{MU}=$ medically unfit for surgery, $\mathrm{N}=$ node, $\mathrm{OS}=$ overall survival, $\mathrm{PD}=$ progressive disease, $\mathrm{SC}=$ squamous cell carcinoma, $\mathrm{T}=$ tumor, undiff $=$ undifferentiated carcinoma, $\mathrm{UPN}=$ unique patient number. ${ }^{a}$ Included with waiver of trial chair.

${ }^{\mathrm{b}}$ Obstructive tumor.

'Tumor located in the lower third of the esophagus with retrojugular lymph node metastasis.

${ }^{\mathrm{d}}$ Mediastinal infiltration.

${ }^{e}$ Extensive mediastinal lymphadenopathy.

${ }^{\mathrm{f}}$ All patients with systemic failure also had local failure.

Table 2. Adverse events during therapy

\begin{tabular}{|c|c|c|c|c|c|c|c|c|}
\hline \multirow[t]{3}{*}{ Adverse events } & \multicolumn{4}{|c|}{ Induction chemotherapy $(\mathrm{n}=21)$} & \multicolumn{4}{|c|}{$\operatorname{CRT}(\mathrm{n}=20)$} \\
\hline & \multicolumn{2}{|c|}{ All grades } & \multicolumn{2}{|c|}{ Grade $3 / 4$} & \multicolumn{2}{|c|}{ All grades } & \multicolumn{2}{|c|}{ Grade 3/4 } \\
\hline & $\mathrm{n}$ & $\%$ & $\mathrm{n}$ & $\%$ & $\mathrm{n}$ & $\%$ & $\mathrm{n}$ & $\%$ \\
\hline Anemia & 21 & 100 & 1 & 5 & 20 & 100 & 1 & 5 \\
\hline Leukopenia & 12 & 57 & 6 & 29 & 10 & 50 & 1 & 5 \\
\hline Neutropenia & 8 & 38 & 6 & 29 & 3 & 15 & 1 & 5 \\
\hline Thrombopenia & 9 & 43 & 1 & 5 & 17 & 85 & 2 & 10 \\
\hline Dysphagia & 16 & 76 & 1 & 5 & 18 & 90 & 3 & 15 \\
\hline Stomatitis & 3 & 14 & 1 & 5 & 0 & 0 & 0 & 0 \\
\hline Diarrhea & 8 & 38 & 1 & 5 & 2 & 10 & 0 & 0 \\
\hline Nausea & 5 & 24 & 1 & 5 & 8 & 38 & 0 & 0 \\
\hline Vomiting & 3 & 14 & 1 & 5 & 2 & 10 & 0 & 0 \\
\hline Alopecia & 13 & 62 & 0 & 0 & 17 & 81 & 0 & 0 \\
\hline Asthenia & 14 & 67 & 0 & 0 & 12 & 57 & 0 & 0 \\
\hline Neurosensory & 1 & 5 & 0 & 0 & 2 & 10 & 0 & 0 \\
\hline Other & 17 & 81 & 4 & 19 & 18 & 90 & 2 & 10 \\
\hline
\end{tabular}

\section{Outcome}

The predefined primary endpoint (histologically confirmed local control 6 months after end of CRT) was achieved in 4 patients $(19 \%)$ based on intention to treat. Consequently, the study was closed prematurely because a rate lower than $30 \%$ was considered clinically ineffective, as stated in the sample size calculation. According to the protocol, patients were counted as local failures if they did not have a biopsy 6 months 
Fig. 2. Overall survival after a median follow-up of 33.7 months $(95 \%$ CI: 29.4-38.2 months); median survival 15.8 months (95\% CI: 12.3-25.6 months).

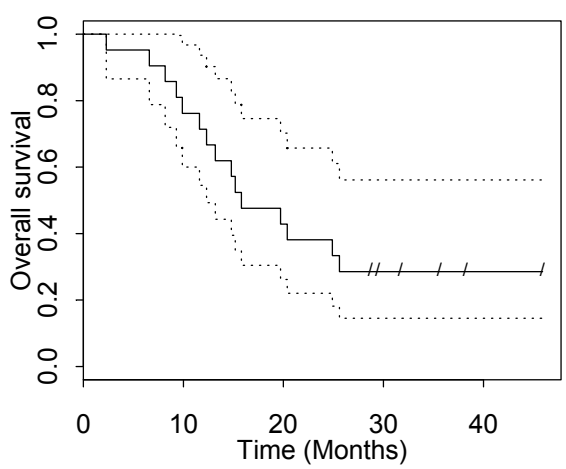

after radiotherapy for any reason (e.g. previous dilatation of the esophagus, patient refusal). 1 patient (UPN 5) refusing biopsies remained disease free for more than 3 years after registration. Therefore, it can be assumed that overall 5 of 21 patients $(24 \%)$ remained free of local and systemic recurrence 6 months after the end of CRT.

Of the other patients, 1 died of herpes simplex hepatitis during CRT (UPN 17), as described above, and 2 died after CRT but before assessment at 6 months, 1 due to local and systemic progression (UPN 2) and 1 due to multiorgan failure after salvage surgery for persistent local tumor (UPN 8). In the remaining 12 patients having finished CRT, there were 9 (43\%) local failures and 3 (19\%) systemic and local failures (fig. 1). The patient who did not receive CRT (UPN 19) experienced systemic and local failure.

After a median follow-up of 33.7 months (95\% confidence interval (CI) 29.4-38.2 months), 6 (29\%) patients were still alive, including 2 with proven local residual disease after CRT, 1 of whom (UPN 18) received subsequent salvage surgery. There were $12(57 \%)$ deaths from progressive disease and $3(14 \%)$ from non-disease-related causes (table 1). Median overall survival was 15.8 months (95\% CI 12.3-25.6 months). The rates of 1 -, 2 - and 3 -year survival were $71 \%$, $38 \%$, and $29 \%$, respectively (fig. 2). Of the 6 surviving patients, 4 had locally very advanced disease at inclusion and the other 2 had been classified as inoperable for medical reasons. Of note, all of these patients were doing well at the time of writing and 4 had no or only minimal dysphagia 12 months after completion of treatment.

\section{Quality of life}

Figure 3 presents the scores for dysphagia, problems with eating, physical well-being, and coping effort at baseline, during therapy, and 3, 6, 9, and 12 months after completion of treatment. At baseline, i.e. before treatment started, all patients $(100 \%)$ completed the questionnaire. The completion rate remained above $80 \%$ throughout the treatment phase. Non-submitted QoL questionnaires were missing due to administrative errors (i.e. questionnaire not presented to the patient). At the 6-month follow-up, $65 \%$ of the surviving patients completed the questionnaire. Except in 1 case, all patients who
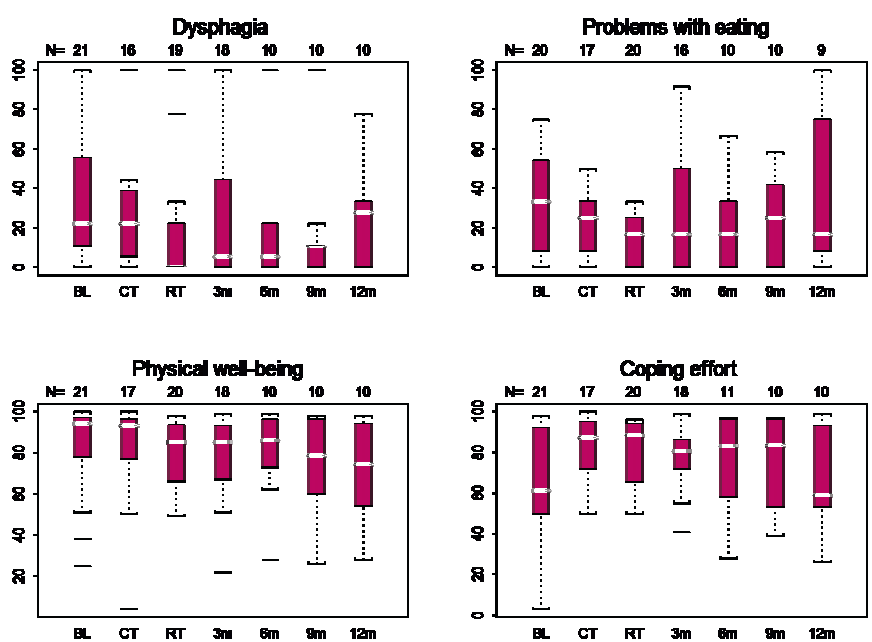

Fig. 3. Quality-of-life scores at baseline, day 1 of cycle 2 of chemotherapy, day 1 of CRT, and 3, 6, 9, and 12 months after completion of treatment. Solid boxes show the 25 th to 75 th percentiles, with horizontal lines indicating median values; whisker bars represent minimal and maximal values of a standard range.

did not complete a questionnaire had either local or systemic failure at this time point and may have felt too ill to answer the QoL questions. Clinically meaningful improvements were observed for dysphagia (median change -11 points) and problems with eating (median change -8.3) from baseline until the completion of induction chemotherapy. These median scores remained low until the 6-month follow-up, but subsequently scores for both dysphagia and problems with eating deteriorated up to the 12-month follow-up. Subjective improvement of dysphagia and problems with eating during induction chemotherapy may be reflected by the fact that it was not necessary to insert feeding tubes during CRT. Feeding tubes were inserted due to stenosis prior to treatment in 7 patients; however, 1 was not needed because of rapid improvement of dysphagia during induction chemotherapy.

The median scores for physical well-being remained within the highest quartile over the whole observation period, representing a rather good overall physical well-being during treatment and for up to 9 months after treatment, followed by a small decline up to the 12-month follow-up. A clinically meaningful improvement in coping effort was observed during treatment (median change of +19 ) and the scores remained at this level for 9 months after treatment.

\section{Discussion}

We prospectively identified a difficult-to-treat group of patients with esophageal carcinoma and disease status between locally advanced and metastatic for whom there is no standard treatment and therapy is often considered palliative. In this group of patients, we prospectively investigated the value 
of an intensified local therapy comprising 2 cycles of induction chemotherapy followed by CRT.

In some centers, patients with M1a disease of the distal esophagus are treated with esophagectomy; however, these patients have a distinctly worse outcome than patients with locally advanced M0 disease [19]. Cervical esophageal cancer is very rare and these patients are usually not included in esophageal cancer trials. Most institutions treat these patients with CRT or radiotherapy alone according to the guidelines for head and neck cancer. The subgroup of patients with locally advanced tumors but medically unfit for surgery is rarely mentioned separately when included in trials of CRT.

In this study, all tumors were staged accurately using CT scan, endosonography and, in most cases, PET scan. The following questions were addressed: How many patients are free of disease as proven by biopsy 6 months after the end of therapy (primary endpoint)? How feasible is such a treatment? And how does it affect the QoL? Formally, the study was negative and was closed prematurely because only $19 \%$ of all patients achieved the primary endpoint and therefore missed the predefined threshold of $30 \%$ for futility. 1 additional patient (UPN 5) showed long-term disease-free survival, but did not achieve the primary endpoint because endoscopic biopsies were not performed after 6 months. Another patient (UPN 18) remains disease free after receiving salvage surgery to treat local tumor progression more than 1 year after study treatment. With hindsight, both the primary endpoint and the threshold may be judged to be too optimistic considering the low compliance with confirmatory biopsies and a cure rate of $20-40 \%$ in operable patients [20-23]. Furthermore, 2 patients died from non-tumor-related causes (herpes simplex hepatitis and complication after rescue surgery) before assessment at 6 months.

Of note, compliance with this intensive treatment regimen was good ( $86 \%$ of all patients completed therapy) and toxicity was manageable. The observed improvement of patient-reported 'dysphagia' and 'problems with eating' and the lack of necessity for additional feeding tubes during CRT supports the proposition that 2 cycles of induction chemotherapy resulted in increased compliance with subsequent CRT, similar to the finding of a previous study in patients with operable tumors [24].

Patients enrolled in this trial are generally considered to have a dismal prognosis. It is therefore notable that 6 of 21 patients were alive after a median follow-up of 34 months, corresponding to a 3 -year survival rate of $29 \%$. Of these patients, 2 were included because of medical contraindications for surgery, while the other 4 had locally very advanced disease. Therefore, these data show that long-term survival can be achieved without surgery even in these poor-risk patients. However, it is difficult to compare our data with the published literature because, in other studies, patients meeting the inclusion criteria for the present trial have been classified using the broad term 'inoperable' $[7,11,25]$. In these studies, there were many diverse reasons for patients being considered inoperable, including older age, comorbidity, advanced stage and the presence of systemic disease. Additionally, not all studies used modern staging methods. The heterogeneity of the inclusion criteria of these studies is reflected by the reported median survival rates widely ranging from 6 to 26 months. However, in one retrospective series [25], about $20 \%$ of patients with T4 stages were described as long-term survivors after CRT as well. None of the 3 patients with cervical esophageal tumors included in the present trial were in the group of long-term survivors. Histology did not predict outcome, and long-term survival was achieved in patients with adenocarcinoma or squamous cell carcinoma.

Despite the intense treatment schedule, QoL was impaired only temporarily in the majority of patients. Of note, even patients experiencing relapse had no or minor dysphagia over a period of 9 months after the end of treatment.

We conclude that this intense treatment schedule is feasible in patients with locally advanced esophageal cancer that is not amenable to potentially curative resection. Moreover, some patients in this poor-prognosis group can achieve longterm survival with this intensive therapy. Although the specified primary endpoint of confirmed local control after 6 months was not met, there was evidence of clinical benefit. Specifically, we observed that relapsing patients also benefited from treatment, as shown by improvements in QoL parameters (dysphagia and problems with eating) and the maintenance of good and stable physical well-being for a considerable period after the end of treatment. Induction chemotherapy and CRT may be an option for selected patients with locally very advanced disease. However, the selection of patients for intensive therapy remains difficult. The present data are limited in this regard because patients with both adenoand squamous cell carcinoma were among the survivors, whereas patients with cervical cancer were not represented, possibly due to an inadequate number of patients enrolled. Further studies are warranted, particularly to identify predictive factors to justify such an intense therapy in those patients most likely to benefit.

\section{Acknowledgement}

We thank Pierluigi Ballabeni for assistance in designing this trial.

\section{Conflict of Interest}

The Swiss Group for Clinical Cancer Research (SAKK) sponsored the trial, and it was financially supported by the State Secretariat for Education and Research, Ministry of Internal Affairs of Switzerland and by sanofi-aventis SA, Switzerland. 
1 Parkin DM, Bray FI, Devesa SS: Cancer burden in the year 2000. The global picture. Eur J Cancer 2001;37(suppl 8):S4-S66.

2 Wong R, Malthaner R: Combined chemotherapy and radiotherapy (without surgery) compared with radiotherapy alone in localized carcinoma of the esophagus. Cochrane Database Syst Rev 2006:CD002092.

$\checkmark 3$ Gebski V, Burmeister B, Smithers BM, Foo K, Zalcberg J, Simes J: Survival benefits from neoadjuvant chemoradiotherapy or chemotherapy in oesophageal carcinoma: a meta-analysis. Lancet Oncol 2007;8:226-234.

$\checkmark 4$ Bedenne L, Michel P, Bouche O, Milan C, Mariette C, Conroy T, Pezet D, Roullet B, Seitz JF, Herr JP, Paillot B, Arveux P, Bonnetain F, Binquet $\mathrm{C}$ : Chemoradiation followed by surgery compared with chemoradiation alone in squamous cancer of the esophagus: FFCD 9102. J Clin Oncol 2007;25: $1160-1168$.

5 Stahl M, Stuschke M, Lehmann N, Meyer HJ, Walz MK, Seeber S, Klump B, Budach W, Teichmann R, Schmitt M, Schmitt G, Franke C, Wilke H: Chemoradiation with and without surgery in patients with locally advanced squamous cell carcinoma of the esophagus. J Clin Oncol 2005;23:2310-2317.

6 Homs MY, v d Gaast A, Siersema PD, Steyerberg EW, Kuipers EJ: Chemotherapy for metastatic carcinoma of the esophagus and gastro-esophagea junction. Cochrane Database Syst Rev 2006: CD004063.

7 Font A, Arellano A, Fernandez-Llamazares J, Casas D, Boix J, Cardenal J, Margeli M, Manzano JL, Abad A, Rosell R: Weekly docetaxel with concomitant radiotherapy in patients with inoperable oesophageal cancer. Clin Transl Oncol 2007;9:177-182.

8 Stuschke M, Stahl M, Wilke H, Walz MK, Oldenburg AR, Stuben G, Jahnke K, Seeber S, Sack H: Induction chemotherapy followed by concurrent chemotherapy and high-dose radiotherapy for locally advanced squamous cell carcinoma of the cervical oesophagus. Oncology 1999;57:99-105.

-9 al-Sarraf M, Martz K, Herskovic A, Leichman L, Brindle JS, Vaitkevicius VK, Cooper J, Byhardt R, Davis L, Emami B: Progress report of combined chemoradiotherapy versus radiotherapy alone in patients with esophageal cancer: an intergroup study. J Clin Oncol 1997;15:277-284.
10 Smith TJ, Ryan LM, Douglass HO Jr, Haller DG, Dayal Y, Kirkwood J, Tormey DC, Schutt AJ, Hinson J, Sischy B: Combined chemoradiotherapy vs. radiotherapy alone for early stage squamous cell carcinoma of the esophagus: a study of the Eastern Cooperative Oncology Group. Int J Radiat Oncol Biol Phys 1998;42:269-276.

11 Wobbes T, Baron B, Paillot B, Jacob JH, Haegele P, Gignoux M, Michel P, Couvreur ML: Prospective randomised study of split-course radiotherapy versus cisplatin plus split-course radiotherapy in inoperable squamous cell carcinoma of the oesophagus. Eur J Cancer 2001;37:470-477.

12 Blazeby JM, Alderson D, Winstone K, Steyn R, Hammerlid E, Arraras J, Farndon JR: Development of an EORTC questionnaire module to be used in quality of life assessment for patients with oesophageal cancer. The EORTC Quality of Life Study Group. Eur J Cancer 1996;32A:1912-1917.

13 Blazeby JM, Conroy T, Hammerlid E, Fayers P, Sezer O, Koller M, Arraras J, Bottomley A, Vickery CW, Etienne PL, Alderson D: Clinical and psychometric validation of an EORTC questionnaire module, the EORTC QLQ-OES18, to assess quality of life in patients with oesophageal cancer. Eur J Cancer 2003;39:1384-1394.

14 Hurny C, Bernhard J, Bacchi M, et al.: The perceived adjustment to chronic illness scale (PACIS): a global indicator of coping for operable breast cancer patients in clinical trials. Swiss Group for Clinical Cancer Research (SAKK) and the International Breast Cancer Study Group (IBCSG). Support Care Cancer 1993;1:200-208.

15 Butow P, Coates A, Dunn S, Bernhard J, Hurny C: On the receiving end. IV: Validation of quality of life indicators. Ann Oncol 1991;2:597-603.

16 Simon R: Optimal two-stage designs for phase II clinical trials. Control Clin Trials 1989;10:1-10.

17 Sloan JA: Assessing the minimally clinically significant difference: scientific considerations, challenges and solutions. COPD 2005;2:57-62.

18 Grimm B, Padberg B, Ruhstaller T, Fleisch F, von Moos R: Fatal herpes simplex virus hepatitis in a patient with esophageal cancer under radiochemotherapy. Onkologie 2008;31:620-622.
9 Trovo M, Bradley J, El Naqa I, Foster E, Meyers B, Govindan R, Patterson A: Esophageal carcinoma with celiac nodal metastases; curative or palliative? J Thorac Oncol 2008;3:751-755.

20 Stahl M, Walz MK, Stuschke M, Lehmann N, Meyer HJ, Riera-Knorrenschild J, Langer P, Engenhart-Cabillic R, Bitzer M, Konigsrainer A, Budach W, Wilke H: Phase III comparison of preoperative chemotherapy compared with chemoradiotherapy in patients with locally advanced adenocarcinoma of the esophagogastric junction. J Clin Oncol 2009;27:851-856.

21 Urba SG, Orringer MB, Turrisi A, Iannettoni M, Forastiere A, Strawderman M: Randomized trial of preoperative chemoradiation versus surgery alone in patients with locoregional esophageal carcinoma. J Clin Oncol 2001;19:305-313.

22 Tepper J, Krasna MJ, Niedzwiecki D, Hollis D, Reed CE, Goldberg R, Kiel K, Willett C, Sugarbaker D, Mayer R: Phase III trial of trimodality therapy with cisplatin, fluorouracil, radiotherapy, and surgery compared with surgery alone for esophageal cancer: CALGB 9781. J Clin Oncol 2008; 26:1086-1092.

23 Ruhstaller T, Widmer L, Schuller JC, Roth A, Hess V, Mingrone W, von Moos R, Borner M, Pestalozzi BC, Balmermajno S, Koberle D, Terraciano L, Schnider A, Bodis S, Popescu R: Multicenter phase II trial of preoperative induction chemotherapy followed by chemoradiation with docetaxel and cisplatin for locally advanced esophageal carcinoma (SAKK 75/02). Ann Oncol 2009;20:1522-1528.

24 Ribi K, Koeberle D, Schuller JC, Honegger H, Roth A, Hess V, Moosmann P, von Moos R, Borner M, Lombriser N, Pestalozzi B, Ruhstaller $\mathrm{T}$ : Is a change in patient-reported dysphagia after induction chemotherapy in locally advanced esophageal cancer a predictive factor for pathological response to neoadjuvant chemoradiation? Support Care Cancer 2009, in press.

25 Crosby TD, Brewster AE, Borley A, Perschky L, Kehagioglou P, Court J, Maughan TS: Definitive chemoradiation in patients with inoperable oesophageal carcinoma. Br J Cancer 2004;90:70-75. 